
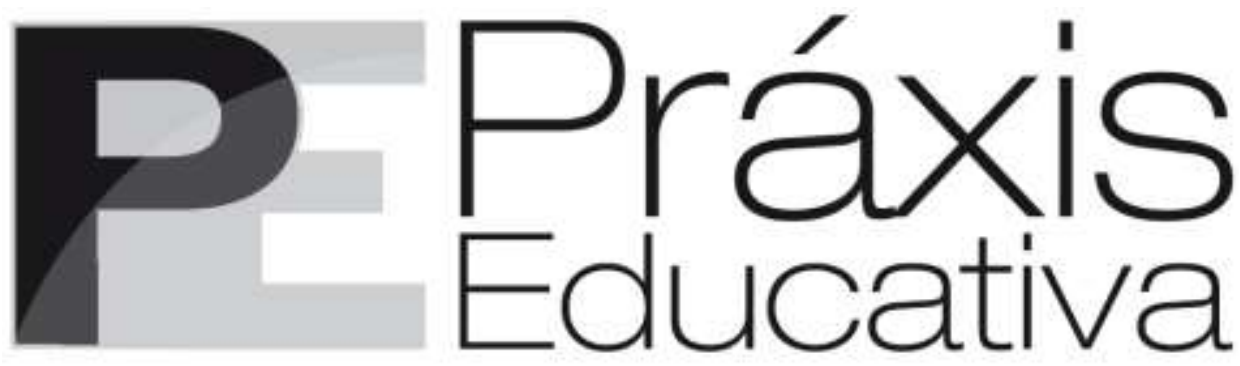

ISSN 1809-4031

elSSN 1809-4309

https://doi.org/10.5212/PraxEduc.v.17.18323.019

Dossiê: Relações étnico-raciais: práticas e reflexões pedagógicas em contextos, espaços e tempos

\title{
Por uma Educação Física antirracista: o protagonismo da Ceafro de Vitória e de Cariacica no Espírito Santo
}

\section{Towards an anti-racist Physical Education: the protagonism of CEAFRO from Vitoria and Cariacica in Espírito Santo}

\section{Por una Educación Física antirracista: el protagonismo de la Ceafro de Vitória y de Cariacica en Espírito Santo}

\author{
Pamela Tavares Monteiro* \\ iD https://orcid.org/0000-0001-9380-0370 \\ José Luiz dos Anjos ${ }^{* *}$ \\ iD https://orcid.org/0000-0002-3440-8982
}

\begin{abstract}
Resumo: Este estudo analisa os programas educacionais étnico-raciais dos últimos dez anos nos municípios de Vitória e de Cariacica, no estado do Espírito Santo. Especificamente, analisa as ações e a sua efetividade e busca identificar a intervenção da Educação Física no contexto desses programas. A metodologia percorreu dois caminhos: a) estudos dos documentos institucionais com as propostas étnico-raciais; b) entrevista semiestruturada com os agentes da Comissão de Estudos Afro-Brasileiros (Ceafro) das Secretarias de Educação dos municípios supracitados. O estudo revelou que os elementos da cultura corporal não constituem instrumentos para a superação dos conflitos raciais no contexto escolar; existem estreitas relações entre a Ceafro e as instituições organizadas da sociedade; e os professores que aderem aos programas são militantes e/ou participantes nas causas étnico-raciais.

Palavras-chave: Educação Física. Étnico-racial. Programas educacionais.
\end{abstract}

\footnotetext{
* Mestranda em Educação Física pelo Programa de Pós-Graduação em Educação Física (PPGEF) da Universidade Federal do Espírito Santo (Ufes); membro do Laboratório de Estudos em Educação Física (Lesef) do Centro de Educação Física e Desporto (CEFD) da Ufes; integrante do Grupo de Estudos EGBÊ (2020-2021); bolsista da Coordenação de Aperfeiçoamento de Pessoal de Nível Superior (Capes). Ênfase de estudo no Ensino das Relações Étnico-Raciais e Educação Física, atuando principalmente nos seguintes temas: epistemologias insurgentes, corpo negro e suas estéticas afrodiaspóricas, empoderamento juvenil e suas re-existências, além de políticas públicas para a população negra. E-mail: <pamelamont@hotmail.com>.

** Professor Titular na Universidade Federal do Espírito Santo (Ufes). Experiência na área de Sociologia, com ênfase em Sociologia do Esporte, atuando principalmente nos seguintes temas: cultura e esporte; jogos tradicionais; questões étnicas raciais no esporte; Educação Física, esporte e sociedade. E-mail: <jluanjos1@hotmail.com>.
}

Práxis Educativa, Ponta Grossa, v. 17, e2218323, p. 1-16, 2022 Disponível em: < https:// revistas2.uepg.br/index.php/praxiseducativa $>$ 


\begin{abstract}
This study analyzes the ethnic-racial educational programs of the last ten years in the municipalities of Vitória and Cariacica, in the state of Espírito Santo, Brazil. Specifically, it analyzes the actions and their effectiveness, and it seeks to identify the intervention of Physical Education within the context of these programs. The methodology followed two paths: a) studies of institutional documents with ethnic-racial proposals; b) semi-structured interview with agents from the Comissão de Estudos Afro-Brasileiros - CEAFRO (departments of African-Brazilian studies) of the Secretariats of Education of the municipalities mentioned above. The study revealed that the elements of corporeal culture are not instruments that are conducive to overcoming racial conflicts existing in the school context; there are close relations between CEAFRO and the organized institutions of society; and the teachers who adhere to such programs are activists and/or participants in ethnic-racial causes.
\end{abstract}

Keywords: Physical Education. Ethnic-racial. Educational programs.

Resumen: El estudio analiza los programas educativos étnico-raciales de los últimos diez años en los municipios de Vitória y Cariacica, en el estado de Espírito Santo, Brasil. Específicamente, analiza las acciones y su efectividad y busca identificar la intervención de la Educación Física en el contexto de esos programas. La metodología siguió dos caminos: a) estudios de los documentos institucionales con las propuestas étnicoraciales; b) entrevista semiestructurada con los agentes de la Comisión de Estudios Afro-Brasileños (Ceafro) de las Secretarías de Educación de los municipios citados. El estudio reveló que los elementos de la cultura corporal no constituyen instrumentos para la superación de los conflictos raciales en el contexto escolar; existen estrechas relaciones entre la Ceafro y las instituciones organizadas de la sociedad; y los profesores que adhieren a los programas son militantes y/o participantes en las causas étnico-raciales.

Palabras clave: Educación Física. Étnico-racial. Programas educativos.

\title{
Introdução
}

A incorporação do tema que trata da educação étnico-racial no currículo brasileiro é uma das questões estruturais que merece investigação na Educação e na Educação Física brasileira (MONTEIRO; ANJOS, 2020). A possibilidade de um trabalho investigativo interdisciplinar sobre o tema em questão pode torná-lo significativo e abrangente, principalmente no âmbito da Educação Física, no qual podemos estimular o trabalho com o corpo, valorizar sua beleza e romper com privilégios étnico-raciais. Uma educação antirracista (BRASIL, 2005) pode oferecer novos olhares formativos, além de reconhecer costumes e tradições trazidos para o Brasil na afrodiáspora. Silvio Almeida, em seu livro O que é Racismo Estrutural?, evidencia o perigo em silenciarmos os racismos, gerando um aumento incalculável dos atos racistas existentes nas instituições (ALMEIDA, 2018), sendo fundamental a valorização e a visibilidade das contribuições afros e indígenas.

Uma educação antirracista baseada na Lei $\mathrm{N}^{0}$ 10.639, de 9 de janeiro de 2003, tem na Educação Física um amplo campo para trabalharmos as possibilidades identitárias, corporais e culturais (BINS; MOLINA NETO, 2017; MOTA E SILVA; QUENZER MATTHIESEN, 2018; PIRES; SOUZA, 2015), além de colaborar para os estudos descoloniais, permite uma maior democratização da educação escolar. Dessa forma, este estudo aborda temas pertinentes à educação étnico-racial nos municípios de Vitória e de Cariacica, no Espírito Santo, relacionados a projetos e/ou programas desenvolvidos no interior das escolas e da Comissão de Estudos Afro-brasileiros (Ceafro), no cumprimento da Lei No 10.639/2003 (BRASIL, 2003), modificada pela Lei No 11.645, de 10 março de 2008, que alterou a Lei de $\mathrm{N}^{\circ}$ 9.394, de 20 de dezembro de 1996, responsável por estabelecer as Diretrizes e Bases da Educação Nacional, para incluir no currículo oficial da rede de ensino a obrigatoriedade da temática "História e Cultura Afro-Brasileira e Indígena" (BRASIL, 2008). Assim sendo, buscamos, neste artigo, analisar os resultados/impactos desses projetos no

Práxis Educativa, Ponta Grossa, v. 17, e2218323, p. 1-16, 2022 Disponível em: < https:// revistas2.uepg.br/index.php/praxiseducativa $>$ 
campo da ação educativa, compreendendo a Educação Física escolar como lócus de desenvolvimento das possíveis temáticas identificadas ${ }^{1}$.

Sendo a Ceafro uma política pública que objetiva propor e avaliar tal temática, a reflexão que oferecemos se sustenta na análise feita dos projetos e/ou dos programas de práticas pedagógicas elaborados a partir da Lei $\mathrm{N}^{\circ} 10.639 / 2003$. Nesse sentido, a pesquisa/reflexão constitui uma investigação inicial sobre essa Lei, instrumento fundamental para uma postura antirracista na Educação, especialmente no que se refere à forma pela qual a memória histórica é concebida pelo saber-fazer escolar. Nosso objetivo geral foi investigar como as Comissões de Estudos Afro-brasileiros relacionam os elementos pedagógicos da escola com as estruturas das políticas públicas, no que tange ao campo da Educação Física escolar no cumprimento da referida lei. O objetivo específico foi identificar como se destacam os discursos sobre os corpos negros no ambiente escolar.

Para cumprimento dos objetivos, a metodologia mais adequada foi a pesquisa exploratória com abordagem qualitativa. O processo metodológico ocorreu de acordo com as três fases da pesquisa: a) Fase exploratória: análise dos documentos, a saber: a Portaria de implementação da Ceafro Vitória (Portaria Nº52/2004); sua atualização (Portaria N 083/2012); Projeto Escolar 1: "Práticas pedagógicas de valorização da vida: trabalhando com as diversidades"; Projeto Escolar 2: "Educação para as relações raciais no Brasil: a importância da discussão racial e as políticas públicas brasileiras em educação"; enquanto Cariacica nos enviou: a Portaria de implementação de sua Ceafro (Portaria $\mathrm{N}^{\circ}$ 03/2015), as leis de referência municipais para as suas ações; ${ }^{2}$ b) Fase de produção de dados: entrevistas com as interlocutoras das Secretarias de Educação dos Municípios de Cariacica e Vitória; c) Fase de análise de dados: discorrer sobre a análise do discurso apresentado pelas comissões e pelos documentos enviados; os materiais utilizados foram gravadores e softwares de reversão áudio-literária.

Inicialmente, realizamos a análise dos documentos escritos e orais, a fim de satisfazermos os objetivos propostos. A investigação inspirou-se nas formulações de Bardin (2011) relativas à análise de conteúdo, as quais se desdobraram no estudo documental anteriormente referenciado. Posteriormente, a partir dos resumos dos documentos, realizamos entrevistas com as duas comissões. Por fim, foram elencadas as categorias temáticas dos pontos a serem investigados e a análise interpretativa dos conceitos que aparecem nos documentos e nas entrevistas.

A análise de conteúdo compreendeu, portanto, a organização e a sistematização dos dados empíricos por meio da pré-análise, a exploração do material, o tratamento dos resultados e sua interpretação (BARDIN, 2011). Empregamos uma análise categorial que funcionou por operações de desmembramento do texto em unidades, em eixos, segundo reagrupamentos estruturais. Entre as diferentes possibilidades de categorização, a investigação dos temas e sua problematização em conjunto, documentos e entrevistas são caminhos eficazes para as análises do discurso (BARDIN, 2011) direto, pois, no decorrer da argumentação, trouxemos à discussão as falas dos interlocutores das Secretarias Municipais de Educação e os documentos apresentados.

As entrevistas ocorreram nas Comissões de Estudos Afro-brasileiros localizadas nas Secretarias de Educação. Tiveram duração de 47 minutos, e o conteúdo tratou exclusivamente das atividades desenvolvidas, das relações entre a Ceafro e as escolas bem como dos participantes das ações, como estudantes, professores, diretores, dentre outros. Textualmente, a denominação de IC

\footnotetext{
${ }^{1}$ Este estudo possuiu financiamento da Fundação de Amparo à Pesquisa e Inovação do Espírito Santo (Fapes).

${ }^{2}$ Os documentos aqui mencionados foram enviados pelas Comissões de Estudos Afro-brasileiros em questão
}

Práxis Educativa, Ponta Grossa, v. 17, e2218323, p. 1-16, 2022 Disponível em: < https://revistas2.uepg.br/index.php/praxiseducativa $>$ 
e IV refere-se às interlocutoras entrevistadas das Secretarias de Educação dos Municípios de Cariacica (IC) e Vitória (IV).

\section{Política de educação étnico-racial nas redes municipais de Vitória e de Cariacica: os documentos em ação}

As relações étnico-raciais constituem-se entre os diferentes grupos sociais e os sujeitos a eles pertencentes. No Brasil, são guiadas por conceitos a respeito de suas distinções e afinidades relacionadas aos grupos aos quais pertencem, estando sujeitos à disputa e ao conflito de espaços. Os conteúdos disciplinares (saber acadêmico), quando optam por seguir uma lógica eurocêntrica hegemônica, privilegiando apenas um continente, universalizam a verdade. Tais conteúdos silenciam outros tipos de ontologias, epistemes e saberes, tratando como não relevantes as heranças das culturas, as corporeidades e as diversidades étnicas de grupos não-brancos. É nesse ângulo que observamos a necessidade de conhecer a política desenhada nas Redes de Educação dos municípios a serem estudados.

A partir da leitura da Portaria No 052/2004, as políticas de implementação e de organização dos projetos e dos programas das questões étnico-raciais, na Secretaria de Educação de Vitória, encontram-se sob a coordenação da Ceafro, vinculada ao Gabinete da Secretaria Municipal de Educação, com o objetivo de "[...] promover estudos e viabilizar ações, com vistas à implementação da Lei no 10.639, de 9 de janeiro de 2003, no âmbito da Rede Municipal de Ensino de Vitória" (VITÓRIA, 2004). A Comissão de Estudos é instituída pelo secretário de Educação e a ela compete “[...] promover e participar da Formação Continuada de professores, gestores e auxiliares em educação, relacionada à temática de Educação multiétnica nas Relações Etnicorraciais de Ensino de História e Cultura Afro-brasileira e Africana" (VITÓRIA, 2004), visando: "Sensibilizar os(as) educadores(as) do Sistema Municipal de Ensino a desenvolverem uma pedagogia pluriétnica e multirracial por meio de cursos de formação, palestras, debates, discussões e similares, no que diz respeito a questões afro-brasileiras" (VITÓRIA, 2004, 2012).

$\mathrm{Na}$ Secretaria de Educação (SEME) de Cariacica, de acordo com a Portaria/SEME No 03, de 6 de abril de 2015, ficou instituído

[...] um grupo de estudo que terá por finalidade, a formulação da minuta de resolução para implementação da criação do ‘CEAFRO' que tem como objetivo construir e elaborar políticas públicas, a partir do plano nacional de implementação das diretrizes curriculares nacionais para a educação das relações étnico-raciais e para o ensino de História e Cultura Afro-Brasileira e Africana da Lei no 10.639/03. (CARIACICA, 2015, p. 3-4).

Tendo como base a existência das Comissões de Estudos Afro-brasileiros, conforme a Portaria $\mathrm{N}^{\circ}$ 052/2004, ou um grupo criado para tal fim, Portaria $\mathrm{N}^{\circ} 03 / 2015$, iniciamos a análise pelas estruturas apresentadas nos documentos recebidos das Coordenações das Secretarias Municipais.

A documentação enviada pela Ceafro de Vitória foi constituída por leis municipais e por ações de acolhimento em casos raciais na escola e, também, em formações que objetivam um projeto a ser desenvolvido pelo servidor público na escola em que este atua. A documentação enviada pela Ceafro de Cariacica foi constituída pelas leis municipais e suas ações formativas para os servidores, com objetivo que estes repensem suas práticas no interior da escola.

Práxis Educativa, Ponta Grossa, v. 17, e2218323, p. 1-16, 2022 


\section{Os projetos da coordenação de estudos das relações étnico-raciais da Ceafro}

Pela Ceafro do município de Vitória, foram-nos apresentados dois documentos, os quais estruturamos de acordo com a proposta metodológica. Para tanto, servimo-nos dos Quadros 1 e 2 a seguir, nos quais podemos visualizar as estruturas de análise.

Quadro 1 - Estruturas de análise contidas nos documentos da SEME de Cariacica/ES

\begin{tabular}{|c|c|c|c|}
\hline $\begin{array}{c}\text { Estrutura conceitual de } \\
\text { análise }\end{array}$ & Documento & Objeto de análise & Interlocução \\
\hline Diversidade & Lei & Intolerância religiosa & Comunidade \\
\hline
\end{tabular}

Fonte: Elaborado pelos autores.

Quadro 2 - Estruturas de análise contidas nos documentos da SEME de Vitória/ES

\begin{tabular}{|c|c|c|c|}
\hline $\begin{array}{c}\text { Estrutura conceitual } \\
\text { de análise }\end{array}$ & Documento & Objeto de análise & Interlocução \\
\hline $\begin{array}{c}\text { Postura política do } \\
\text { educador }\end{array}$ & Projeto & $\begin{array}{c}\text { Reflexões } \\
\text { pedagógicas }\end{array}$ & Professores e educadores \\
\hline "Práticas pedagógicas" & Projeto & $\begin{array}{c}\text { "Superação de } \\
\text { conceitos" }\end{array}$ & Professores, diretores de escolas etc. \\
\hline Diversidade & Projeto & $\begin{array}{c}\text { Raça, gênero, } \\
\text { sexualidade }\end{array}$ & $\begin{array}{c}\text { Professores, educadores e Instituições } \\
\text { organizadas }\end{array}$ \\
\hline
\end{tabular}

Fonte: Elaborado pelos autores.

Os documentos os quais constituem projetos escolares da Ceafro da SEME de Vitória apresentam percursos similares nos processos de aplicação dos dispositivos legais educacionais constitutivos da Lei $\mathrm{N}^{\circ} 10.639 / 2003$. Consideramos que as similitudes e as coincidências representam práticas e conteúdos recorrentes na oferta da educação.

No que tange ao campo da Educação Física, as formações oferecidas pelas Comissões de Estudos Afro-brasileiros são fundamentais para romperem estereótipos e estigmas raciais, pois, como nos afirmam o estudo de Pires e Souza (2015), há perigo em se apresentar conteúdo da cultura afro na Educação Física sem uma preocupação quanto à subversão das lógicas coloniais reproduzidas pelas escolas. As pesquisas sobre formação de professores (MOTA E SILVA; QUENZER MATTHIESEN, 2018, p. 127) demonstram as surpresas que alguns profissionais possuem ao descobrirem as manipulações eugenistas do início do século XX geradores de estereótipos e estigmas racializantes. Os autores também problematizam o fato de alguns professores compreenderem a capoeira como único conteúdo afro a ser ofertado.

Dessa forma, a primeira estrutura comum identificada nos documentos é a postura política do educador, isto é, a quem são destinados os cursos oferecidos. São professores, coordenadores, diretores, pedagogos e servidores da Rede Municipal de Ensino. A primeira pergunta ${ }^{3}$ realizada visou compreender a iniciativa do servidor para realização do curso. IV diz que:

$$
\begin{aligned}
& \text { [...] a gente aprende muito nessas formações, é que a gente não está no espaço de militância, a gente está } \\
& \text { num espaço [...] está, como militante, porque a gente não faz as coisas pelo salário que a gente ganha, } \\
& \text { que é muito baixo, mas a gente farporque ama muito, e isso é muito caro para nós. }
\end{aligned}
$$

Para ambas as coordenações, o que faz construir projetos sólidos no contexto escolar é a militância do servidor público. Essa mesma análise podemos identificar na fala da IC quando trata das leis municipais existentes em Cariacica. Para a IC, a conquista, de "[...] tudo [enfatizou] que se dir. étnico-racial é pela militância. Se eu não fosse uma professora militante, nós não teríamos esse setor instituído na (rede)". Percebemos que a opção pela construção de educadores militantes não é idealista, mas no

\footnotetext{
${ }^{3}$ As perguntas pautam-se no documento apresentado pela SEME de Vitória.
}

Práxis Educativa, Ponta Grossa, v. 17, e2218323, p. 1-16, 2022 Disponível em: <https:// revistas2.uepg.br/index.php/praxiseducativa> 
intuito de fazer da militância um elemento orientador da formação continuada do docente. Isso é o que tem dado sentido à práxis dos educadores.

Embora os dois documentos apresentados não façam menção à militância, parece haver uma preocupação com os desdobramentos dos projetos nas escolas. Tal fato pode ser observado quando a IV salienta que, no processo de formação/curso, uma instituição adere à proposta do projeto:

[...] esse é um projeto institucional: não é dele, do diretor; é da instituição, é da escola toda. Ele envolve pedagogas, coordenadoras, diretor, então todo mundo executa o projeto de forma ampla na escola, geral, com todas [enfatizou] as turmas.

Estabelecemos, aqui, uma reflexão importante: no caso da escola, o trabalho coletivo, apesar de constituir preocupação mais recente, nem sempre encontra aceitação por parte dos diretores ou mesmo dos professores que, por força do hábito de trabalhar isoladamente, veem em uma nova proposta uma tarefa suplementar. As escolas deveriam funcionar como instituições de resistência e de transformação desses discursos que impõem normas, regulam e naturalizam os corpos, enquanto deveriam criar contextos socioeducativos em que os grupos étnico-minoritários e femininos pudessem afirmar sua identidade, "[...] por sua própria voz, autorrepresentação e construção do senso de suas experiências de incorporação por meios que consideram relevantes" (AZZARITO, 2016, p. 145, tradução nossa). Como o currículo poderia ser reescrito "[...] para empoderar meninas e garotos de diferente etnicidades e classes sociais para expressar suas capacidades corporais livre e completamente, e aprender sobre as regras fundamentais da atividade física em suas vidas”? (AZZARITO; SOLOMON, 2005, p. 40, tradução nossa).

Discorrendo sobre o "trabalho coletivo", há algumas limitações para essa perspectiva: a cultura do "individualismo" na atividade docente e um possível "praticismo" para o qual bastaria a prática para a construção do saber docente. Constrói-se, portanto, um possível "individualismo", resultante de uma reflexão em torno de si próprio, consistindo em uma posição autoritária, quando se considera a reflexão como elemento suficiente para resolver os problemas da prática docente.

Essa reflexão tem continuidade, pois o "projeto institucional" demonstra preocupação com a "cultura do individualismo" que envolve a prática docente, em contraposição ao ambiente de cooperação que deveria presidir a realização do trabalho educativo coletivo. O trabalho isolado limita as possibilidades de o professor ter uma avaliação mais ampla e objetiva, uma vez que ele não é objeto de exposição e de análise. Restringe, assim, as possibilidades de melhoria, o que nos permite criar uma intervenção em que tudo o que se faz pode ser avaliado, com o objetivo de o professor marcar sua presença no contexto escolar e nas instâncias institucionais.

Contudo, há problemas que se manifestam na possibilidade do desenvolvimento de um projeto na escola e que estão diretamente ligados à saúde e à lida diária do professor, pois, de acordo com IV, “[...] hoje, nós ainda estamos em marco, a pessoa [professor] já está esgotada, porque o cotidiano da escola é uma loucura, e ela trabalha o dia todo com muita criança. E aí essa pessoa vai ter estímulo como, para vir fazer o curso à noite?".

Essa fala abre espaço para dois fatores que, devido à estrutura institucional, não nos permitem identificar a solidificação na formação e na participação dos educadores. O primeiro está relacionado ao cumprimento da carga horária, pois, segundo IV: "Na educação infantil os professores de Educação Física, Arte e Música não têm. Isso não existe, não temos curso dentro do borário de trabalho". O segundo fator é o que defende a IC, quando discute a formação continuada dos professores, tendo como proposta temáticas étnico-raciais. Para a IC, quanto à formação de educadores, "[...] nunca teve um espaço de formação dentro do calendário escolar. Essa é uma das grandes lutas nossas".

Práxis Educativa, Ponta Grossa, v. 17, e2218323, p. 1-16, 2022 Disponível em: < https:// revistas2.uepg.br/index.php/praxiseducativa $>$ 
Ao final, vimos que, de acordo com a interlocutora de Vitória, não há formação específica para essa área ou outra, depende da adesão que o professor faz ao curso. Para a IC, até o momento, não houve formação ou curso para os professores pois a interlocutora se posiciona de forma contrária à organização de formação de professores "fora" do horário de trabalho. Parece-nos que não se trata de fortalecimento de voluntariado, mas que o próprio município faça adesão à proposta de formação. Nessa relação antagônica, desde a formação da Ceafro do município de Cariacica, as formações ocorreram por meio de palestras e de eventos formativos em parceria com os movimentos negros organizados e a universidade pública.

A problemática da formação continuada refere-se a propostas que aspiram um novo modelo de conteúdo, agora mais diverso e inclusivo, diferente do tradicional que, durante muito tempo, esteve atrelado às questões hegemônicas. Tal mudança gera dificuldades para os educadores ressignificarem e promoverem rupturas com os conteúdos oficiais consolidados. Esses desafios, atualmente, de forma analítica, situam-se nos campos dos processos relacionais, englobando fatores educacionais. Nesse sentido, uma das interlocutoras, por exemplo, reitera que os projetos a serem desenvolvidos em conjunto com a Ceafro beneficia toda a escola, não devendo ser compreendido somente como um projeto pontual desenvolvido por um diretor e/ou professor. Em sua fala, ela afirma: "[...]é um projeto institucional... não é dele [referindo-se ao diretor da escola]" (IV).

$\mathrm{Na}$ escola, os atores, entre si, estabelecem relações com os processos que podem se caracterizar, em sua essência, com o saber acadêmico; contudo, essas relações têm, de uma forma geral, um caráter essencialmente social e coletivo. Assim, temos de considerar e perguntar: Será que os vários elementos (das formações) que compõem os novos contextos de interpretações passam a regular as relações no contexto escolar?

Em efeito, percebemos que o caráter da Lei No 10.639/2003 é plural. Sua aplicação é responsabilidade de toda a comunidade escolar, uma vez que o maior desafio consiste na superação do preconceito entre todos os atores que encenam e contracenam no palco escolar, todos expostos aos mesmos referenciais que pairam sobre a população negra no Brasil, enfim, sobre a cultura afrobrasileira.

Um ponto em comum aos projetos configura-se, bem a propósito, como uma apropriação particular do instrumento legal - e ambos se fundamentam mais na lei do que no seu conhecimento. Essa análise faz-se necessária, pois não identificamos, em nenhum momento, conteúdos que tratam da Lei $\mathrm{N}^{\circ} 10.639 / 2003$. De forma geral, os conteúdos são considerados como se o conhecimento da lei já estivesse fundamentado e apreendido pelos professores ${ }^{4}$.

Os projetos buscam dar conta daquilo que os professores consideram fundamental - a reparação de uma injustiça, por meio da valorização dos atributos morais/valorativos relacionados ao povo afro e afro-brasileiro. Nesse sentido, os projetos possuem dificuldades em avançar nos conteúdos sobre o conhecimento acadêmico acerca da África, dos africanos e da cultura afrobrasileira, de modo sistemático, pois as formulações existentes ainda se baseiam nos discursos amplos e diversos, presentes nas pautas dos movimentos organizados, dificilmente aderidos pelas instituições políticas e escolares.

Assim, notamos possibilidades de desconstrução de ideologias hegemônicas e etnocêntricas existentes nos conteúdos oficiais, operando, assim, como estímulo para o pensamento crítico e

\footnotetext{
${ }^{4}$ Diz respeito ao Projeto Escolar 1: Conhecer as relações raciais desde a formação do Brasil e toda a contextualização de implementação de políticas públicas voltadas à composição sócio-histórica do país é de fundamental importância na discussão e na promoção da aplicação das Leis $N^{\circ} 10.639 / 2003$ e N ${ }^{\circ} 11.645 / 2008$ e dos vários contextos que provocam a desigualdade no acesso e na permanência à educação.
}

Práxis Educativa, Ponta Grossa, v. 17, e2218323, p. 1-16, 2022 Disponível em: < https:// revistas2.uepg.br/index.php/praxiseducativa> 
solidário de toda a comunidade escolar. A desconstrução faz-se na ênfase à ideologia do branqueamento com o objetivo de compreender a influência de tal ideologia nos processos de construção das subjetividades da geração afro, ainda tão presente nos conteúdos escolares. Outra ideologia presente no viés capitalista, que pode ser desconstruída, é da inferiorização, a começar pelo aspecto econômico-consumista, pois a população negra é a que mais se encontra na "classe pobre". Além disso, no caso dos afro-brasileiros, a inferiorização dada pela cor, a qual, por ser uma marca, um estigma, faz com que essa população não tenha um lugar garantido na sociedade, porque é a partir dessa característica de marca visível, que foi simbolizada historicamente, que se aponta, ainda hoje, quem é o negro no Brasil e qual é ou não é o seu lugar (ANJOS, 2006).

Isso nos leva à segunda estrutura comum entre os projetos analisados, a busca pelo respeito, pela inclusão e pela diversidade na escola. Verificamos que as atividades se voltam mais para a formação ética e moral do que para o enfrentamento de conteúdos didáticos disciplinares - como os de caráter historiográfico, geográfico, linguístico ou literário. Pensadas como momentos de valorização da herança africana, as atividades estabelecem pouca relação com a crítica antirracista ao conteúdo didático formal e projetam discursos de transformação das relações entre os grupos sociais, baseados nas noções de tolerância, de respeito à diferença e à diversidade. ${ }^{5}$

O caráter pontual das iniciativas é outro traço comum entre os projetos analisados e as interlocuções, que pode ser percebido em suas abordagens adotadas: os projetos enfatizam os caracteres éticos e morais relacionados com a temática e destacam os elementos de confronto que lhes são atribuídos. ${ }^{6}$ A análise dos documentos disponíveis demonstra, no entanto, que as atividades concentram esforços no trato da superação das temáticas e da história oficial. Por fim, constituem traços comuns entre os projetos estudados: o planejamento e a execução.

Ainda que o discurso contido nos documentos delegue aos professores participantes a autoria e a condução dos projetos a serem implantados nas escolas, a pesquisa evidencia e analisa o quanto esses projetos são dependentes da participação de um grupo de professores de disciplinas específicas: os docentes de História, de Língua Portuguesa e de Artes - o que foi evidenciado. Aqui, reside o objeto principal que estamos buscando: a participação da Educação Física em consubstanciar a Lei $\mathrm{N}^{\circ}$ 10.639/2003 na operacionalização pedagógica no contexto escolar. Se temos, como objetivo, suscitar a reflexão sobre a possibilidade da inclusão na aplicabilidade no campo da Educação Física escolar, como desenvolver as temáticas nas aulas dessa disciplina na concepção conceitual, procedimental ou atitudinal, partindo do professor?

Se concebermos a escola como espaço democrático, o saber acumulado e a visão crítica dos educadores podem gerar mudanças que promovem a ressignificação de valores já estabelecidos na sociedade. É ingênuo pensar que, em um jogo de uma dada modalidade esportiva não residam elementos que comportem subjetividades dominantes "étnicas" e "sociocêntricas", isto é, classificações cognitivas e fisiológicas em face às outras culturas e expressões corporais.

Entendendo que professores são agentes ativos na construção de sua própria prática sem esquecer que estão em interação com os demais e imersos nas limitações da escola, sem qualquer prolixidade, analisamos que a necessidade de formação continuada em campos e em áreas específicas é necessária, pois as rupturas de paradigmas de conhecimentos podem não ser críticas ou rompidas durante a formação acadêmica. Esse conhecimento, cristalizado pela força social de classe, é levado para as escolas. Cada professor com seus conteúdos. Assim, elementos como

\footnotetext{
${ }^{5}$ Trata-se do Projeto Escolar 2, intitulado "Literatura infantil, juvenil e para jovens e adultos e suas abordagens raciais. Reflexões no contexto escolar".

${ }^{6}$ Diz respeito ao Projeto Escolar 1, cujo foco de discussão foram as diversidades por meio da linguagem no módulo: "Exercitando a escrita de si. Abordando as diversidades: localizando o preconceito dentro de mim".
}

Práxis Educativa, Ponta Grossa, v. 17, e2218323, p. 1-16, 2022 Disponível em: < https:// revistas2.uepg.br/index.php/praxiseducativa $>$ 
racismo, preconceito, raça/etnia, gênero etc. são percepções existentes no espaço escolar, vividas pelo professor, mas não vivenciadas no que tange ao contexto escolar, conforme atesta Coelho (2018) em seus estudos acerca do estado da arte sobre a formação de professores e as relações étnico-raciais.

Para Daolio (1995), a transmissão cultural exige capacidades de subjetividades e de representação. Toda continuidade cultural se perderia se não houvesse a possibilidade de serem conservadas e transmitidas às gerações seguintes. A escola e seus componentes curriculares possuem a tarefa de transmitir a memória cultural e os valores produzidos historicamente pelas/nas relações sociais. Nesse contexto, pensar o corpo negro e repensar a Educação Física como produto cultural e discursivo nos faz refletir que toda mudança é permeada por relações de poder, a partir de inúmeras possibilidades de significações biológica, cultural e social, pois o corpo expressa a história acumulada de uma sociedade (ANJOS; QUINTÃO, 2016).

A operacionalidade dos projetos das políticas educacionais nas escolas, a partir da Lei $\mathrm{N}^{\circ}$ 10.639/2003, ocorre em uma via de mão dupla. Argumentamos essa possibilidade no momento em que a IV salienta: "Porque não é um tema que vai ser distribuido. A gente não pensa assim. É o contrário. São profissionais de diferentes áreas que vêm abarcar um tema com o que ele trabalha na escola...[...]". Por sua vez, a IC enfatiza que "[...] ainda não há um foco na Educação Física”. Desse modo, os conteúdos são ministrados sem uma distribuição disciplinar, mas, sim, por temática, a exemplo apontamos o racismo religioso, os preconceitos de gênero e de classe, a autoestima e o empoderamento de crianças e de jovens.

Como os projetos não indicam as disciplinas participantes, identificamos, então, uma tentativa de pedagogizar as temáticas, cada qual ao campo de estudo do professor. Em nosso caso, estamos atentos à Educação Física. Para a IV, é um "tema específico" que abrange o conjunto interdisciplinar: "[...] quando a gente faz as grades do curso, de quem vai vir conversar, a gente pensa. Fala: 'Olha, a gente tem um público diferenciado. São professores de diversas áreas'. Então, normalmente, se vai falar de literatura, a professora de português lembra de falar [...]”.

Ao analisar as diferentes áreas que abarcam um tema, refletimos acerca dos saberes dos educadores no contexto escolar. Tardif (2008, p. 36) apresenta o saber docente como "[...] um saber plural, formado pelo amálgama, mais ou menos coerente, de saberes oriundos da formação profissional e de saberes disciplinares, curriculares e experienciais". É oportuno, aqui, falar sobre os saberes experienciais valorizados e desenvolvidos pelos professores no âmbito de sua atuação profissional. Partem, assim, do babitus do professor como sujeito e como coletividade (TARDIF, 2008). Portanto, a contextualização das formações oferece possibilidade de suscitar experiências realizadas no cotidiano escolar. Essa experiência de que nos fala Tardif (2008) pode ser transposta para os componentes de conhecimentos da Educação Física.

Os municípios de Cariacica e de Vitória apresentam similarmente temáticas e objetos semelhantes, embora em contextos distintos. O município de Cariacica, pela Lei $\mathrm{N}^{\circ}$ 4.479, de 31 de maio de 2007, tem como objetivo "[...] realizar ou apoiar eventos que tenham por objetivo combater a intolerância religiosa" (CARIACICA, 2007, n.p.), no plano da estrutura conceitual da "diversidade". Já no município de Vitória, a questão da religiosidade é enfocada nas "relações raciais" e nas "práticas pedagógicas". Nossa argumentação caminha em direção às experiências do professor e ao que a ele é oferecido. As interlocutoras IV e IC apresentam os embates existentes no cotidiano escolar. Para a IV, com referência à "intolerância religiosa",

[...] a gente não usa mais. A gente usa a expressão "racismo religioso". Então, nós lembramos, nessa área, que, no módulo do curso que teve essa abordagem do racismo religioso, houve uma polêmica gigantesca... E ai teve professor, inclusive da Umbanda ou do Candomblé, com as suas guias que se

Práxis Educativa, Ponta Grossa, v. 17, e2218323, p. 1-16, 2022 Disponível em: < https://revistas2.uepg.br/index.php/praxiseducativa $>$ 
Por uma Educação Física antirracista: o protagonismo da Ceafro de Vitória e de Cariacica...

manifestaram... [...]. Então foi um curso inflamado de quatro horas [...], a gente ficou quatro horas falando apenas sobre isso.

Para a IC, situação semelhante ocorre nos contextos da escola, pois, em face às manifestações que se apresentam "[...] há um confronto de cultura religiosa" entre os principais atores que constituem o cenário escolar: professores e alunos.

Teves (1992) esclarece que, para investigar uma realidade social, é preciso contar com um conjunto coordenado de representações, uma estrutura de sentidos e de significados que circula entre membros de determinados grupos sociais, mediante diferentes formas de linguagem, alicerçando e construindo ações. Contudo, parece-nos que a estratégia de enfrentamento desses embates não se restringe apenas as do plano pedagógico, de saberes docentes e dos conjuntos de conteúdos e de disciplinas oferecidos. As condições reais de intervenção amparam-se em atitudes unilaterais, não levando em conta a práxis pedagógica nem o sentido político-pedagógico de confrontação do objeto posto em pauta de discussão (diversidade).

Os temas analisados permitem-nos, mais uma vez, indicar o objeto que ainda apresenta dificuldade de aceitação entre os grupos que se antagonizam simbolicamente às relações étnicoraciais no interior da escola e na sociedade, negligenciando a Educação Física e seus conteúdos de luta e de danças pautados na cultura afro-brasileira. Ao analisarmos as leis municipais do município de Cariacica, não identificamos possibilidades de enfrentamentos utilizando o corpo, a arte, a música, enfim, as expressões corporais identitárias. ${ }^{7}$ Os Parâmetros Curriculares Nacionais - PCN (BRASIL, 1997) inclusive levantam essas possibilidades: é preciso considerar que a linguagem do corpo e a linguagem das artes em geral transversalizem, particular e pedagogicamente, a Educação Física e a Arte. Podemos vincular as expressões culturais, em geral, aos diferentes grupos étnicos, constituindo manifestações culturais identitárias, as quais socialmente podem ser contextualidadas, de forma decolonial, conhecidas, e, se possível, vivenciadas, a exemplo do Congo e/ou do Tícumbi no estado do Espírito Santo.

A capoeira, as danças e as plasticidades corporais afro-brasileiras, como práticas culturais, são significativas de valores e, como conteúdo da Educação Física, trazem a valorização de sua herança africana por meio de um sistema ético-estético próprio, calcado em valores específicos que guardam relação com símbolos afrodescendentes. Para esta discussão, chamamos Anjos (2013), que, ao estudar as danças e as manifestações populares do norte do Espírito Santo, revelou que essas práticas estão carregadas de expressões simbólicas religiosas, as quais são manifestadas coletiva e individualmente.

Acreditamos ser salutar discutir o rompimento de determinados conceitos no interior dos conteúdos e nas formações acadêmicas dos educadores, o que nos leva à terceira estrutura de análise: o saber pedagógico do educador e sua relação com a Educação Física no interior na escola. Trata-se de uma questão crucial no contexto da prática docente: a necessidade de repensar a alienação pedagógica que se denota pela impossibilidade de o professor objetivar as circunstâncias, por tomar as suas práticas como objeto de valor em si, ou seja, não pensar a práxis pedagógica como práxis social da qual ele participa.

É preciso, portanto, romper com a individualidade, evitando problemas que são evidentes no processo real do trabalho pedagógico: o professor vai expressando uma atuação solitária e fragmentada no cotidiano da escola e, cada vez mais, reduz a sua autonomia como sujeito instituinte

\footnotetext{
7 A Lei No 4.656, de 4 de setembro de 2008, que dispõe “[...] sobre a política municipal de promoção da igualdade racial de Cariacica e dá outras providências" (CARIACICA, 2008, n.p.), as quais são objetos de análise, não fazem referência direta e específica de elementos artísticos e de expressões corporais identitárias.
}

Práxis Educativa, Ponta Grossa, v. 17, e2218323, p. 1-16, 2022 Disponível em: < https:// revistas2.uepg.br/index.php/praxiseducativa $>$ 
na construção do Projeto Político-Pedagógico (PPP); utiliza métodos e conteúdos de forma mecânica, provenientes de "pacotes curriculares"; avalia em uma abordagem essencialmente técnica, pautada na eficiência do processo de avaliação: adere, sobretudo, a uma prática reiterativa, não criadora/criativa. E o mais agravante: imerso nesse contexto, muitas vezes o professor não se apercebe da problematização da sua atividade e da fragilidade da sua prática para enfrentar novas formas de organização e de relação com o conhecimento, portanto suas ideias acabam formando um engessamento em sua consciência de educador, dando-lhe um sentido e uma direção em oposição ao trabalho pedagógico coletivo. Dessa forma, muitas vezes, o docente estabelece uma relação de exterioridade com a sua atividade, como se ela não lhe pertencesse (o conteúdo não é meu!) e, com isso, acaba aprisionado ou se sujeitando ideologicamente, perdendo sua condição de sujeito social concreto e criativo em sua lida cotidiana de ensinar.

Retomando a questão central desta análise, é importante ressaltarmos que a religiosidade africana e a europeia/católica foi ressignificada em solo americano, constituindo-se em um elemento extremamente importante de coesão da identidade das classes populares. Se, em um primeiro momento, permaneciam as divisões étnicas e de classe, em um momento posterior restava apenas a origem como fator de identidade que habilmente foi reforçado por elementos culturais, como a religião popular, a dança e a capoeira.

Aqui, reiteramos que, no universo da capoeira, há uma grande abertura para múltiplas religiosidades e saberes que vão muito além do ato motor. Como descreveu Brito (2011), há diversos elementos de um "catolicismo popular" que ocupam um lugar de destaque na capoeira, como a referência a santos, como São Bento, São Benedito e Santo Antônio, presentes em canções e em nomes de toques de berimbau. Há também uma abertura para o cristianismo evangélico, porém isso não significa uma total ruptura com o afro religioso, constituindo antes uma série de continuidades facilmente observável, principalmente na ritualística neopentecostal, conforme Silva $(2005,2007)$.

Parece que os programas educacionais e as leis publicadas, nesse caso os legisladores, desconhecem as possibilidades de a Educação Física promover intervenções em conjunto e/ou interdisciplinarmente aos diversos componentes curriculares do Projeto Pedagógico da escola; no entanto, a Educação Física sequer é mencionada nos documentos analisados em ambas as coordenações de estudos afros. Entretanto, existem conteúdos que se revelam como potenciais lócus dos princípios de discussão das questões afro e raciais na escola. Há, porém, importantes contextos em que isso pode ocorrer. É a possível identificação entre praticar uma arte (capoeira) e fazer desta um instrumento de desvelamento de conflitos étnicos, culturais e simbólicos. Seguindo nessa linha, além da prática da capoeira e de atividades suplementares com distintas temáticas culturais, a exibição de filmes seguida de debates dos alunos traz a possibilidade de eles entrarem em contato com o universo da temática da diversidade religiosa na sociedade, utilizando a capoeira como instrumento pedagógico para esse fim.

A Educação Física, que tem o corpo e o movimento como seu objeto de conhecimento, busca, nas matrizes teóricas da Biologia e das Ciências Sociais, suas epistemes para pedagogizar suas ações e suas intervenções na escola. Estaria, portanto, a capoeira sendo pedagogizada no viés das relações étnico-raciais? Estaria o esporte sendo tematizado no contexto das rupturas dos conhecimentos biológicos tão arraigados na Educação Física? Que expressões corporais demandam a identidade étnica-racial na escola? Estariam o hip hop e outras danças regionais atuando como produtoras de cultura e de arte e se constituem como elementos sociais políticos para sentirse ouvidos?

A Educação Física assim como outros campos pedagógicos poderiam acessar esses elementos carregados de símbolos para serem utilizados como instrumentos de rupturas dos

Práxis Educativa, Ponta Grossa, v. 17, e2218323, p. 1-16, 2022 Disponível em: < https://revistas2.uepg.br/index.php/praxiseducativa $>$ 
conteúdos tradicionais, os quais, por muito tempo, se mantiveram na continuidade de representações que excluem a identidade étnico-racial. No entanto, sabemos da dificuldade presente na Educação Física de superar a visão pedagógica predominantemente "eurocêntrica", buscando se apropriar das manifestações que afirmam incisivamente a cultura afro-brasileira e indígena, a exemplo da capoeira, do samba-de-roda, do maculelê, do maracatu etc. Todavia, essa superação é muito cara à Educação Física. Tal dificuldade decorre da percepção de que a Educação Física encontra, em seu percurso histórico, uma série de eventos sociorraciais que conflitam para a superação antirracista, em que associar o seu objeto de investigação à questão étnico-racial é ter de rediscutir a sua própria história.

\section{Considerações finais}

Tendo em vista nossos objetivos, foi possível concluirmos, nesta pesquisa, que as Comissões de Estudos Afro-Brasileiros, mesmo oferecendo ações tanto no que diz respeito à formação de projetos afrorreferenciados nas escolas quanto no enfrentamento antirracista no cotidiano escolar, possuem limites quanto ao racismo institucional. Ao relacionarmos os elementos pedagógicos da escola com as estruturas das políticas educacionais, não identificamos trabalhos ou abordagens com a cultura do corpo negro. Não podemos diluir essa constatação após análises dos documentos, das entrevistas e das interpretações realizadas, nas quais não identificamos nenhuma menção à Educação Física como possibilidade de protagonizar rupturas dos elementos pertinentes à temática étnico-racial na escola.

Em relação à análise dos discursos sobre os corpos negros no ambiente escolar, identificamos que os elementos/conceitos identificados nos documentos vêm expondo possibilidade de articulação das diferenças étnico-raciais e procurando/buscando promover rupturas no ato pedagógico. Contudo, a possibilidade de emergir essas rupturas torna-se mais tênue quando há propostas de enfrentamentos de determinados conceitos e de representações sociais incrustradas nos agentes produtores dos conteúdos dos componentes curriculares na escola.

Pareceu-nos também que, para esses enfrentamentos, a Educação Física, componente que trabalha com o corpo e o movimento, não se apresenta como instrumento para a superação das cristalizações tradicionais pedagógicas. Podemos citar a capoeira que poderia ser a resposta às intolerâncias religiosas sob os registros de denúncia ao racismo no espaço de relações entre elementos simbólicos afro-brasileiros e o espaço político institucional.

Este estudo limitou-se a ouvir as comissões das Secretarias de Educação Municipais. Poderíamos ouvir os professores, mas eles serão objeto de pesquisa em outra oportunidade. No entanto, ao analisarmos as interlocuções, não vimos, nos documentos/programas e nas falas das interlocutoras dos municípios pesquisados, elementos culturais, artísticos, de movimento corporal que pudessem ser referência de desenvolvimento da cultura afro-brasileira no contexto escolar. A capoeira é citada; contudo, parece desconsiderar as questões sociais, históricas e culturais envolvidas nesse tema/nesse conteúdo. Isso representa, por parte da escola, a continuidade de um projeto que serve a uma sociedade excludente. Nesse sentido, entendemos que de nada adianta inserirmos conteúdos (mesmo culturais e étnicos), em uma relação conteúdo-método, sem considerarmos a relação dialética professor-aluno-conhecimento necessária nos processos de ensino e de mudança.

Mudar conteúdo e método, necessariamente, exige mudar nossos objetivos e nossas concepções. Mesmo com todo o discurso de inclusão que a Lei $N^{\circ} 10.639 / 2003$ apresenta, se conservarmos os objetivos da escola liberal, incluiremos a exclusão. Azzarito, Simon e Marttinen (2017, p. 206) argumentam que professores de “[...] Educação Física necessitam repensar e

Práxis Educativa, Ponta Grossa, v. 17, e2218323, p. 1-16, 2022 Disponível em: < https:// revistas2.uepg.br/index.php/praxiseducativa $>$ 
recolocar a agenda da justiça social na direção das atuais inequidades produzidas pela globalização, cuja característica é homogeneizar pessoas jovens na incorporação de normas monoculturais".

Deixamos evidente que o estudo das relações étnico-raciais na Educação Física deve conduzir a uma reflexão sobre corpo e poder e desvelar até que ponto essas relações influenciam a produção de estereótipos. Assim como Silva e Moreira (2010), defendemos, também, que corpo, movimento e cultura como campos de estudos da Educação Física são temáticas que, potencializadas dentro e fora da escola, podem colaborar para o reconhecimento das desigualdades culturais e educacionais produzidas pelo fenômeno do racismo, assim como deter seus efeitos contemporâneos. Também pensamos que é preciso avançarmos na discussão sobre a Lei $\mathrm{N}^{\circ}$ $10.639 / 2003$, dimensionando a tensão entre sua aplicabilidade e suas propostas, pois entendemos que "desconstruir" conceitos e combater preconceitos demandam militâncias políticas - por que não dizer militância pedagógica, que precisa ser exercitada na escola em forma de interesse comum e interdisciplinar.

Diante desse questionamento, atentamos para alguns desafios quando propomos trabalhar com os elementos das questões étnico-raciais, pautados no ensino da Educação Física, problematizando as relações de hierarquias e de classificações construídas historicamente. Ademais, a corporalidade que expressa valores identitários e estéticos de matriz étnico-racial, negra e indígena, deve ser apropriada e considerada como corporalidade que não se resume à biologia, à fisiologia ou à estética de movimentos, mas, sim, dotada de identificações culturais e de estéticas étnico-raciais.

Importa, em um plano teórico-metodológico interdisciplinar, fazer com que essas considerações repercutam de forma mais efetiva na escola. Justificamos esse último desejo como uma sugestão para que o estudo da cultura corporal na escola básica e na formação de professores se torne significativo e contribua para fazer avançar as questões étnico-raciais na escola com a cultura corporal de movimento exercendo seu protagonismo de trabalhar com o corpo.

Como discussão final, vimos dificuldades para concluir os estudos, pois nossos argumentos e nossas interpretações analíticas se envolveram nos conflitos políticos, em um cenário conturbado de inquietações e de denúncias das políticas públicas. Isso nos permitiu experimentar deslocamentos epistemológicos relativamente arriscados em uma conclusão de estudos, pois não temos subsídios na Educação Física brasileira para essa discussão. No entanto, concluímos que, para atingir os objetivos da Educação e da Educação Física, incluindo nas ações pedagógicas voltadas às novas narrativas, isso só será possível se for superada a fragmentação do conhecimento. Então, não teríamos uma proposta para a História; teríamos, sim, uma proposta para a Educação, como forma de ampliar o trabalho pedagógico no que for possível por meio de decisões e de estratégias internas à escola, com clareza de limites de cada componente. Para finalizarmos, enfatizamos que essa discussão, tão ausente na Educação Física, é necessária para construirmos gênesis de marcos discursivos das políticas educacionais, da Educação Física, da escola e da Lei $\mathrm{N}^{\circ}$ $10.639 / 2003$.

\section{Referências}

ALMEIDA, S. L de. O que é racismo estrutural?. Belo Horizonte: Letramento, 2018.

ANJOS, J. L. dos. Festa, danças e representações: continuidade de tradições e plasticidades culturais. Movimento, Porto Alegre, v. 19, n. 3, p. 11-30, jul./set. 2013. DOI: https://doi.org/10.22456/1982-8918.36533

Práxis Educativa, Ponta Grossa, v. 17, e2218323, p. 1-16, 2022 Disponível em: < https://revistas2.uepg.br/index.php/praxiseducativa $>$ 
ANJOS, J. L.; QUINTÃO, F. (org.). Educação física, corpo e tradição: o jogo das comunidades tradicionais. Curitiba: Appris, 2016.

ANJOS, R. S. dos. Quilombolas: tradições e cultura de resistência. São Paulo: Aori Comunicação, 2006.

AZZARITO, L. "Permission to Speak": A postcolonial view on racialized bodies and PE in the current context of globalization. Research Quarterly for Exercise and Sport, [s. l.], v. 87, n. 2, p. 141-150, 2016. DOI: $\underline{\text { https://doi.org/10.1080/02701367.2016.1166474 }}$

AZZARITO, L.; SIMON, M.; MARTTINEN, R. 'Up against whiteness': rethinking race and the body in a global era. Sport, Education and Society, [s.l.], v. 22, n. 5, p. 635-657, 2017. DOI: http://dx.doi.org/10.1080/13573322.2015.1136612

AZZARITO, L.; SOLOMON, M. A reconceptualization of Physical Education: the intersection of gender/race/social class. Sport, Education and Society, [s. l.], v. 10, n. 1, p. 25-47, 2005. DOI: https://doi.org/10.1080/135733205200028794

BARDIN, L. Análise de Conteúdo. São Paulo: Edições 70, 2011.

BINS, G. N.; MOLINA NETO, V. Mojuodara: uma possibilidade de trabalho com as questões étnico-raciais na educação física. Revista Brasileira de Ciências do Esporte, Porto Alegre, v. 39, n. 3, p. 247-253, 2017. DOI: https://doi.org/10.1016/j.rbce.2017.02.009

BRASIL. Lei No 10.639, de 9 de janeiro de 2003. Altera a Lei no 9.394, de 20 de dezembro de 1996, que estabelece as diretrizes e bases da educação nacional, para incluir no currículo oficial da Rede de Ensino a obrigatoriedade da temática "História e Cultura Afro-Brasileira", e dá outras providências. Diário Oficial da União: seção 1, Brasília, DF, n. 8, p. 1, 10 jan. 2003.

BRASIL. Lei No 11.645, de 10 março de 2008. Altera a Lei nº 9.394, de 20 de dezembro de 1996, modificada pela Lei $\mathrm{n}^{\circ} 10.639$, de 9 de janeiro de 2003, que estabelece as diretrizes e bases da educação nacional, para incluir no currículo oficial da rede de ensino a obrigatoriedade da temática "História e Cultura Afro-Brasileira e Indígena". Diário Oficial da União: seção 1, Brasília, DF, n. 48, p. 1, 11 mar. 2008.

BRASIL. Secretaria de Educação Fundamental. Parâmetros Curriculares Nacionais: introdução aos Parâmetros Curriculares Nacionais. Secretaria de Educação Fundamental. Brasília: MEC, SEF, 1997.

BRASIL. Educação Antirracista: caminhos abertos pela Lei Federal n. 10.639/03. Brasília: Ministério da Educação, SECAD, 2005.

BRITO, C. de. A mobilização dos símbolos religiosos na capoeira: sincretismos e antissincretismos. Debates do NER, Porto Alegre, v. 12, n. 19, p. 53-75, 2011. DOI: https://doi.org/10.22456/1982-8136.25785

CARIACICA. Lei No 4.479, de 31 de maio de 2007. Institui o "Dia municipal de combate à intolerância religiosa" e dá outras providências. Cariacica: Câmara de Cariacica, [2007]. Disponível em:

http://www3.camaracariacica.es.gov.br/Arquivo/Documents/legislacao/html/L44792007.html. Acesso em: 31 jan. 2022.

CARIACICA. Lei $\mathbf{N}^{\mathbf{0}} \mathbf{4 . 6 5 6}$, de 4 de setembro de 2008. Dispõe sobre a política municipal de promoção da igualdade racial de Cariacica e dá outras providências. Cariacica: Câmara de Cariacica, 
[2008].

Disponível

em: http://www3.camaracariacica.es.gov.br/Arquivo/Documents/legislacao/html/L46562008.html. Acesso em: 31 jan. 2022.

CARIACICA. Portaria/SEME/ No 03, de 6 de abril de 2015. Cria grupo especial e dá outras providências. Diário Oficial do Município: Cariacica, ES, n. 90, p. 3-4, 7 abr. 2015. Disponível em: https://ptdocz.com/doc/763809/diario-oficial-municipal-07-04-2015-assinado-. Acesso em: 31 jan. 2022.

COELHO, W. N. B. Formação de professores e relações étnico-raciais (2003-2014): produção em teses, dissertações e artigos. Educar em Revista, Curitiba, v. 34, n. 69, p. 97-122, maio/jun. 2018. DOI: https://doi.org/10.1590/0104-4060.57233

DAOLIO, J. A construção cultural do corpo feminino, ou o risco de transformar meninas em "antas". In: ROMERO, E. (org.). Corpo, mulher e sociedade. Campinas: Papirus, 1995. p. 99108.

MONTEIRO, P. T.; ANJOS, J. L. dos. A Educação Física e a identidade étnico-racial: o estado da arte nas revistas brasileiras de Educação Física. Motrivivência, Florianópolis, v. 32, p. 61, p. 1-20, 2020. DOI: https://doi.org/10.5007/2175-8042.2020e62154

MOTA E SILVA, E. V.; QUENZER MATTHHIESEN, S. Atletismo e Ensino da História e Cultura Afro-brasileira: visão de professores de Educação Física participantes de um curso de extensão a distância. Movimento, Porto Alegre, v. 24, n. 1, p. 119-132, mar. 2018. DOI: https://doi.org/10.22456/1982-8918.75789

PIRES, J. V. L.; SOUZA, M. da S. Educação Física e a aplicação da Lei no 10.639/03: análise da legalidade do ensino da cultura afro-brasileira e africana em uma escola municipal do RS. Movimento, Porto Alegre, v. 21, n. 1, p. 193-204, fev. 2015. DOI: https://doi.org/10.22456/1982-8918.46624

SILVA, M. C. de P. M.; MOREIRA, A. de J. A Lei no 10.639/03 e a Educação Física: memórias e reflexões sobre a educação eugênica nas políticas de formação de professores. In: COLÓQUIO INTERNACIONAL EDUCAÇÃO E CONTEMPORANEIDADE, 4., 2-13, 2010, Laranjeiras. Anais eletrônicos [...]. Laranjeiras: Educon, 2010. Disponível em: https://ri.ufs.br/bitstream/riufs/10343/66/65.pdf. Acesso em: 31 jan. 2022.

SILVA, V. G. da. Neopentecostalismo e religiões afro-brasileiras: significados do ataque aos símbolos da herança religiosa africana no Brasil contemporâneo. Mana, Rio de Janeiro, v. 13, n. 1, p. 207-236, 2007. DOI: https://doi.org/10.1590/S0104-93132007000100008

SILVA, V. G. da. Concepções religiosas afro-brasileiras e neopentecostais: uma análise simbólica. Revista USP, São Paulo, n. 67, p. 150-175, 2005. DOI: https://doi.org/10.11606/issn.2316$\underline{036 . v 0 i 67 \mathrm{p} 150-175}$

TARDIF, M. Saberes docentes e formação profissional. Petrópolis: Vozes, 2008.

TEVES, N. Imaginário social e educação. Rio de Janeiro: Gryphus/Faculdade de Educação da UFRJ, 1992.

VITÓRIA. Prefeitura Municipal de Vitória. Secretaria de Educação. Portaria No 052, de 17 de agosto de 2004. Vitória, 2004. 
Por uma Educação Física antirracista: o protagonismo da Ceafro de Vitória e de Cariacica...

VITÓRIA. Prefeitura Municipal de Vitória. Secretaria de Educação. Portaria $\mathbf{N}^{\mathbf{o}} \mathbf{0 8 3}$, de 5 de março de 2012. Vitória, 2012.

Recebido em 09/07/2021

Versão corrigida recebida em 26/01/2022

Aceito em 27/01/2022

Publicado online em 04/02/2022

Práxis Educativa, Ponta Grossa, v. 17, e2218323, p. 1-16, 2022

Disponível em: < https:// revistas2.uepg.br/index.php/praxiseducativa $>$ 